Article

\title{
Heteropolyacid Salt Catalysts for Methanol Conversion to Hydrocarbons and Dimethyl Ether: Effect of Reaction Temperature
}

\author{
Yuehong Yu ${ }^{1}$, Daoming Sun ${ }^{1}$, Shuanjin Wang ${ }^{1}{ }^{1}$, Min Xiao $^{1, *}$, Luyi Sun $^{2}{ }^{\circledR}$ and \\ Yuezhong Meng $1, *$ (i) \\ 1 The Key Laboratory of Low-Carbon Chemistry \& Energy Conservation of Guangdong Province/State Key \\ Laboratory of Optoelectronic Materials and Technologies, Sun Yat-sen University, Guangzhou 510275, China; \\ yuyueh@mail2.sysu.edu.cn (Y.Y.); sundm@mail2.sysu.edu.cn (D.S.); wangshj@mail.sysu.edu.cn (S.W.) \\ 2 Polymer Program, Institute of Materials Science and Department of Chemical \& Biomolecular Engineering, \\ University of Connecticut, Storrs, CT 06269, USA; luyi.sun@uconn.edu \\ * Correspondence: stsxm@mail.sysu.edu.cn (M.X.); mengyzh@mail.sysu.edu.cn (Y.M.); \\ Tel./Fax: +86-20-8411-4113 (Y.M.)
}

Received: 24 February 2019; Accepted: 26 March 2019; Published: 1 April 2019

\begin{abstract}
Phosphotungstic and silicotungstic acid salt catalysts (CuPW, CuSiW, FePW, FeSiW) were synthesized by substitution of protons with ferric and copper ions through a simple replacement reaction. The structure and thermal stability were characterized by IR, XRD and TG, and the salts showed a keggin structure and a thermal tolerance near $450^{\circ} \mathrm{C}$. Temperature programmed reactions indicated that the four catalysts showed similar trends in the change of methanol conversion, DME selectivity, and light olefins selectivity at $100-400{ }^{\circ} \mathrm{C}$. Copper salt catalysts showed a $100 \% \mathrm{DME}$ selectivity at temperatures ranging from $100-250{ }^{\circ} \mathrm{C}$, while $\mathrm{FeSiW}$ and $\mathrm{FePW}$ catalysts had a $100 \%$ DME selectivity near $250{ }^{\circ} \mathrm{C}$. Moreover, the heteropolyacid salt catalysts also produced a certain number of light olefins at the temperature ranging from $250-350{ }^{\circ} \mathrm{C}$, and the $\mathrm{CuSiW}$ catalyst exhibited the highest ethylene and propylene selectivity of $44 \%$. In the stability test evaluated at $200{ }^{\circ} \mathrm{C}$, the catalysts showed different tendencies during the induction period and the same trends during the reduction period for the methanol conversion to DME, due to the differences in the strengths of the strong acid sites. Finally, the silicotungstic acid salt catalysts showed the longest lifetime of $120 \mathrm{~h}$, much longer than the heteropolyacids. This approach provides an effective way to synthesize hydrocarbons through methanol, especially DME, at different temperatures using one catalyst.
\end{abstract}

Keywords: methanol to hydrocarbons; heteropolyacid salts; dimethyl ether; temperature programmed reaction

\section{Introduction}

Methanol is among the top 10 commercial chemicals with wide applications, including chemical intermediates and fuels [1]. Among them, the most important are the reactions of methanol conversion to hydrocarbons, especially dimethyl ether (DME) and light olefins. Dimethyl ether is one of the most promising compounds because of its mild physical and chemical properties and wide application in energy and environmental fields [2,3]. Dimethyl ether has no corrosiveness to metals, skin irritation, or carcinogenicity, and has low-environmental harm due to its low level of nitrous oxides during its particulates emission combustion process, hence, it was honored as a clean energy in the 21st century [3-5]. Currently, DME is mainly used as an aerosol propellant and refrigerating fluid, as well as a substitution for diesel due to its high-octane value, burning properties, and low emissions [6-8]. Dimethyl ether can also be a substitution for liquefied petroleum gas (LPG) for civil use because its 
readily compressible and has a high heat of combustion [8,9]. Moreover, DME is also a useful chemical stock for many important reactions such as high-selective synthesis of propylene [10,11], methylation reaction for dimethyl sulfate [12], carbonylation reaction for ethyl acetate and acetic anhydride [13], and oxidation reaction for formaldehyde [14]. On account of the ever-increasing demand, more attention is paid to the synthesis of DME.

Currently, there are two main routes for DME synthesis in industrial production [15,16]. One is the one-step synthesis of syngas to DME over a high-activity and high-stability bi-functional catalyst which combines the formation and dehydration of the methanol process, the typical catalyst is a mixture of a $\mathrm{Cu} / \mathrm{Zn}$-based catalyst with a solid-acid catalyst like $\gamma-\mathrm{Al}_{2} \mathrm{O}_{3}$ [17-20]. Another route is the direct synthesis of DME through methanol dehydration over a solid-acid catalyst $[8,21]$. The main solid-acid catalysts used are $\gamma-\mathrm{Al}_{2} \mathrm{O}_{3}$, composite oxides like $\mathrm{SiO}_{2}-\mathrm{Al}_{2} \mathrm{O}_{3}, \mathrm{TiO}_{2}-\mathrm{ZrO}_{2}$, and $\mathrm{SiO}_{2}-\mathrm{TiO}_{2}$, sulfated $\mathrm{ZrO}_{2}$, metal salts like $\mathrm{AlPO}_{4}, \mathrm{Al}_{2}\left(\mathrm{SO}_{4}\right)_{3}$, and zeolites [17,22-29]. Despite the high methanol conversion capacity, they need high operation temperatures due to the low acid concentration, which results in undesired by-products such as light hydrocarbons and coke that will reduce the DME production and deactivate the catalysts [30-32].

Recently, some researchers began to focus on the catalytic performance of heteropolyacids (HPAs) in methanol conversion to DME reaction and obtained excellent performance, they exhibit high reaction rates at much lower reaction temperatures [30,33-40]. The main drawbacks of HPAs are the low surface area and high acid strength, which cause strong interactions between $\mathrm{H}_{2} \mathrm{O}$ molecules and the acid sites of the HPAs [33]. The commonly used solution is to disperse the catalyst on the high surface area carrier, and these catalysts are more active and resistant than the corresponding bulk HPAs for the dehydration of methanol to DME $[33,41,42]$. The conversion of methanol to hydrocarbons over heteropolyacid salt catalysts were studied $[43,44]$. The catalyst activities of different metal salts of heteropolyacids were also compared, and copper salt and ferric salt catalysts showed high activities [44]. In this article, we synthesized a series heteropolyacid salt catalysts which substitute protons with $\mathrm{Cu}^{2+}$ and $\mathrm{Fe}^{3+}$ ions using a simple method to decrease the acid density. Then, we studied the catalytic performance for the methanol conversion to hydrocarbons in a temperature programmed process and the stability performance of the methanol to DME reaction for the first time. Temperature programmed reactions showed an extremely high DME selectivity (100\%) and a certain amount of light olefins production at different reaction temperatures. Meanwhile, the catalysts showed a 120-h lifespan for the methanol to DME reaction at $200{ }^{\circ} \mathrm{C}$, which is a quite low reaction temperature for the reaction of methanol to DME.

\section{Results and Discussion}

\subsection{Characterization of the Catalysts}

\subsubsection{Structure and Thermal Stability of Heteropolyacid Salts}

Fourier transform infrared spectroscopy (FTIR) was applied to study the structure of heteropolyacid salts and the results are shown in Figure 1a-c. There were four typical peaks for phosphotungstic acid and silicotungstic acid, respectively. In Figure 1a, the four characterization peaks $1080 \mathrm{~cm}^{-1}, 984 \mathrm{~cm}^{-1}, 888 \mathrm{~cm}^{-1}$, and $803 \mathrm{~cm}^{-1}$ could be assigned as a P-Oa asymmetric stretch, $\mathrm{W}=\mathrm{Ot}$ asymmetric stretch, $\mathrm{W}-\mathrm{Ob}-\mathrm{W}$ asymmetric stretch, and a W-Oc-W asymmetric stretch [45-47]. The peaks in Figure $1 \mathrm{~b}$ can be assigned as $980 \mathrm{~cm}^{-1}$ (W=Ot asymmetric stretch), $927 \mathrm{~cm}^{-1}$ (Si-Oa asymmetric stretch), $878 \mathrm{~cm}^{-1}$ (W-Ob-W asymmetric stretch), and $789 \mathrm{~cm}^{-1}$ (W-Oc-W asymmetric stretch), while the peak at $1020 \mathrm{~cm}^{-1}$ is still difficult to be assigned [48]. Figure 1a,b indicate that the heteropolyacid ions retain the characteristic of keggin structure after the reaction with salts. The thermal stability of the CuPW and CuSiW were then studied to check the thermal tolerance of keggin structure. The IR results are shown in Figure $1 \mathrm{c}, \mathrm{d}$, and the typical peaks for the phosphotungstic structure remain clear until $450{ }^{\circ} \mathrm{C}$. However, they thoroughly disappear upon $500{ }^{\circ} \mathrm{C}$ treatment, which manifest a thermal tolerance at temperatures ranging from $450{ }^{\circ} \mathrm{C}$ to $500^{\circ} \mathrm{C}$ for the keggin structure. 
The result is consistent with the results reported in Reference [33]. As for the silicotungstic structure, the typical peaks began to disappear when subjected to the treatment at $450{ }^{\circ} \mathrm{C}$, indicating a thermal tolerance ranging from $400{ }^{\circ} \mathrm{C}$ to $450^{\circ} \mathrm{C}$.
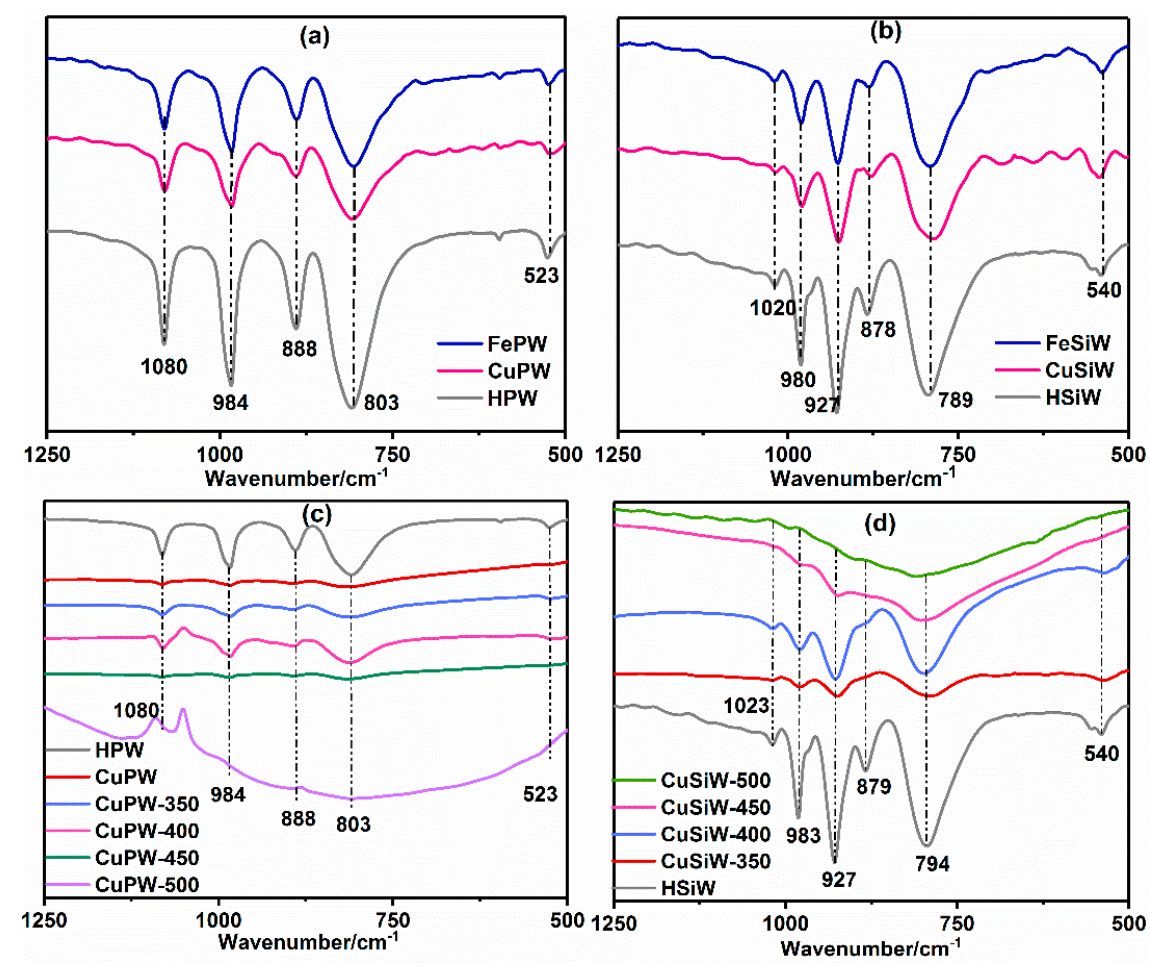

Figure 1. FTIR spectra of the as-synthesized samples: (a) HPW, CuPW, FePW; (b) HSiW, CuSiW, FeSiW; comparison of (c) CuPW samples and (d) CuSiW samples calcined at different temperatures under air atmosphere. 350/400/450/500 means samples were calcined at the corresponding temperature.

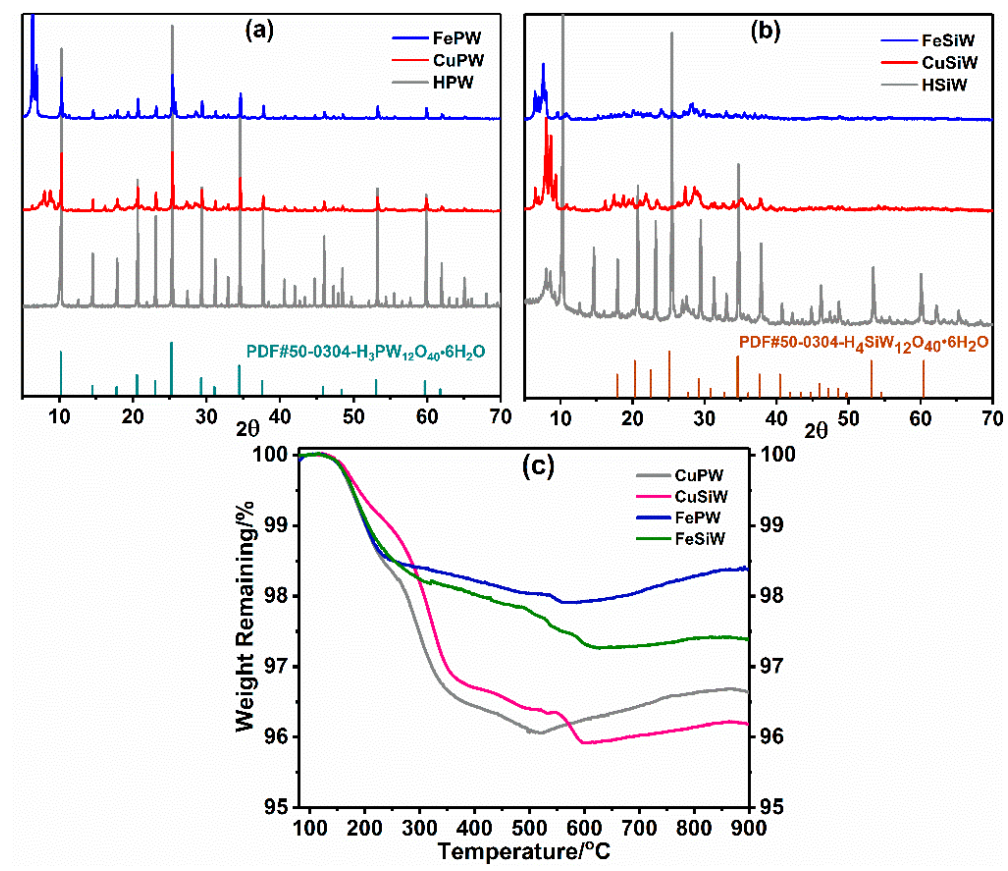

Figure 2. XRD patterns of the as-synthesized samples: (a) HPW, CuPW, FePW; (b) HSiW, CuSiW, FeSiW. (c) TG profiles of the as-synthesized samples (pre-treated at $120^{\circ} \mathrm{C}$ for $0.5 \mathrm{~h}$ ). 
XRD (X-ray diffraction) patterns were recorded to characterize the phase composition of synthesized heteropolyacid salts, and the results are presented in Figure 2a,b. The peaks of the salts were different with corresponding acids, indicating the formation of salts. The typical peaks of HPW can be seen in the phosphotungstic acid salt while the no-acid phase existed in the silicotungstic acid salt, implying that the phosphotungstic acid salts existed with more acid impurities than the silicotungstic acid salts catalyst.

The TG (Thermogravimetry) analyses were carried out to confirm the weight change during the heating process and the results are shown in Figure $2 c$, all the samples show a light weight loss $(<5 \%)$ till $900{ }^{\circ} \mathrm{C}$. The sharp weight loss stage of $\mathrm{CuPW}$ and $\mathrm{CuSiW}$ ended at $350{ }^{\circ} \mathrm{C}$ while the sharp stage for ferric salts ended at $250{ }^{\circ} \mathrm{C}$, whilst the mild step for both salts ended near $600{ }^{\circ} \mathrm{C}$. The platform till $150{ }^{\circ} \mathrm{C}$ indicated the successful removal of the physically adsorbed water during the pre-treatment process. The stage between $150^{\circ} \mathrm{C}$ to $350^{\circ} \mathrm{C}$ can be assigned to the chemically crystalline water, which ends at different temperature indicating the different ability of affinity to water for copper and ferric salts. The second weight loss stage between $500{ }^{\circ} \mathrm{C}$ to $600{ }^{\circ} \mathrm{C}$ represents the destruction of keggin structure to oxides [30], being consistent with the IR results.

\subsubsection{Composition and Textural Properties of Heteropolyacid Salt Catalysts}

Nitrogen adsorption-desorption measurement was applied to characterize the textual properties of the heteropolyacid salt samples, and the results are shown in Table 1 and Figure 3. All samples have a hysteresis loop in the high relative pressure region (type-IV isotherms) and scarcely any type I isotherms which increase rapidly under low-relative pressure, proving the main existence of mesopores, which corresponds with the micropore volume and mesopore volume shown in Table 1. The DFT (Density functional theory) pore-size distribution indicates that the mesopore mainly ranged between 5-50 nm. The ratios of mesopore volume and macropore volume are also shown in Table 1 . The average pore diameter for copper salts were very close, while the values for ferric salts were smaller. All heteropolyacid salt samples had a quite low BET surface area $\left(<5 \mathrm{~m}^{2} \cdot \mathrm{g}^{-1}\right)$ due to the low volume of pores. The ICP-OES (Inductively coupled plasma optical emission spectrometry) was used to characterize the ratio of $\mathrm{W} / \mathrm{M}(\mathrm{W} / \mathrm{Cu}$ or $\mathrm{W} / \mathrm{Fe})$ and the results are shown in Table 1 . The experimental results are less than the theoretical $\mathrm{W} / \mathrm{M}$ ratio, implying that the hydrogen ions were not completely substituted by metal ions. The substitution ratios of metal ion for CuPW and FePW were smaller than the CuSiW and FeSiW catalysts, which corresponds with the XRD results in Figure 2.
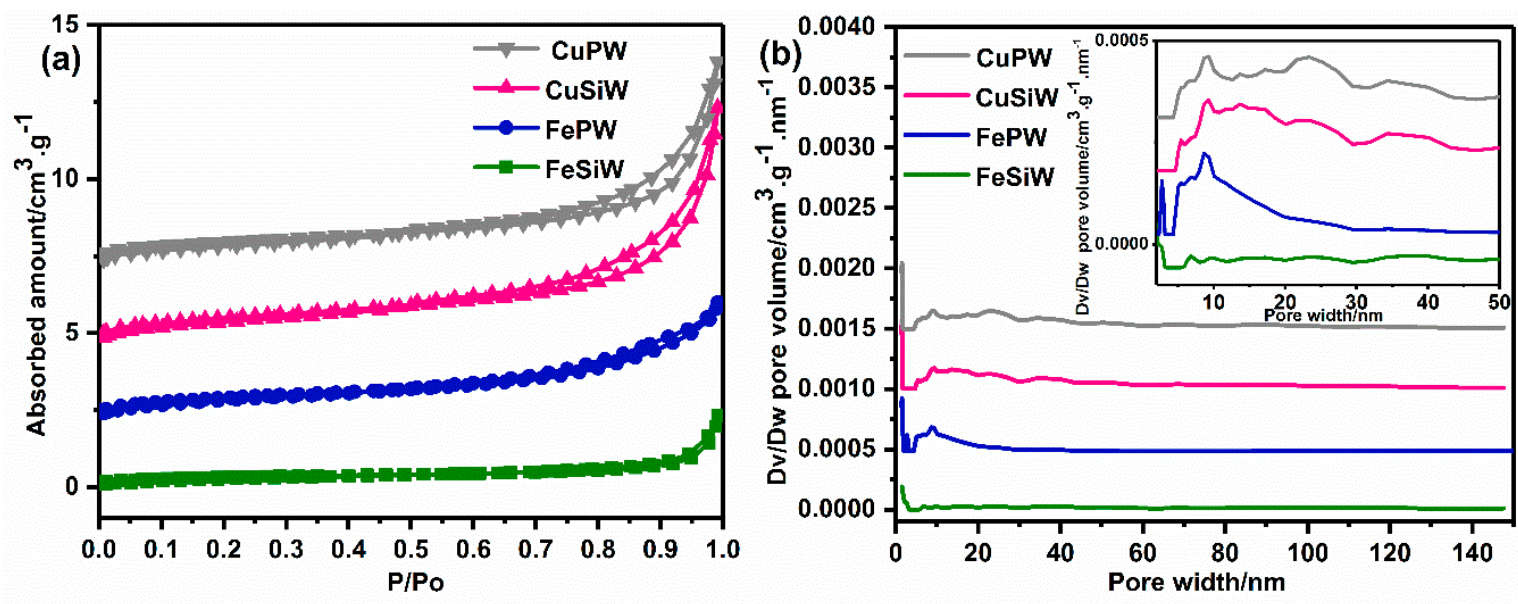

Figure 3. (a) $\mathrm{N}_{2}$ adsorption/desorption isotherms and (b) DFT pore size distribution curves of the as-synthesized heteropolyacid salt samples. 
Table 1. Compositions and textural properties of the as-synthesized heteropolyacid salt samples.

\begin{tabular}{|c|c|c|c|c|c|c|c|c|c|c|}
\hline $\begin{array}{l}\text { Sample } \\
\text { Name }\end{array}$ & $\mathbf{W} / \mathbf{M}^{\mathrm{a}}$ & $\mathrm{W} / \mathrm{M}_{\text {theo }}$ & $\begin{array}{l}S_{\text {BET }} b \\
\left(m^{2} / g\right)\end{array}$ & $\begin{array}{l}S_{\text {micro }}{ }^{c} \\
\left(m^{2} / g\right)\end{array}$ & $\begin{array}{c}S_{\text {ext }}{ }^{c} \\
\left(m^{2} / g\right)\end{array}$ & $\begin{array}{l}V_{\text {micro }}{ }^{c} \\
\left(\mathrm{~cm}^{3} / \mathrm{g}\right)\end{array}$ & $\begin{array}{l}V_{\text {meso }}{ }^{d} \\
\left(\mathrm{~cm}^{3} / \mathrm{g}\right)\end{array}$ & $\underset{\%}{\mathbf{R}_{\text {Meso }}}{ }^{\mathrm{e}}$ & $\underset{\%}{\mathbf{R}_{\text {Macro }}}{ }^{\mathrm{e}}$ & $\begin{array}{c}\text { Average } \\
\text { Pore Size } \\
\text { (nm) }\end{array}$ \\
\hline CuPW & 6.75 & 8 & 3.05 & 0.56 & 2.49 & $2.34 \cdot 10^{-4}$ & $1.03 \cdot 10^{-2}$ & 62.5 & 37.5 & 13.48 \\
\hline $\mathrm{CuSiW}$ & 5.56 & 6 & 3.48 & 0.22 & 3.26 & $5.10 \cdot 10^{-5}$ & $1.20 \cdot 10^{-2}$ & 62.1 & 37.9 & 13.73 \\
\hline $\mathrm{FePW}$ & 9.44 & 12 & 3.41 & 0.91 & 2.50 & $3.69 \cdot 10^{-4}$ & $6.42 \cdot 10^{-3}$ & 76.0 & 24.0 & 7.28 \\
\hline $\mathrm{FeSiW}$ & 8.35 & 9 & 1.21 & 0.31 & 0.90 & $1.05 \cdot 10^{-4}$ & $3.51 \cdot 10^{-3}$ & 38.8 & 61.2 & 11.42 \\
\hline
\end{tabular}

${ }^{\mathrm{a}}$ Measured by inductively coupled plasma (ICP), W/Cu or W/Fe. ${ }^{\mathrm{b}} \mathrm{S}_{\mathrm{BET}}$ (total surface area) calculated by applying the BET equation using the linear part $(0.05<\mathrm{P} / \mathrm{Po}<0.30)$ of the adsorption isotherm. ${ }^{c} \mathrm{~S}_{\text {micro }}$ (micropore area), $\mathrm{S}_{\text {ext }}$ (external surface area), and $\mathrm{V}_{\text {micro }}$ (micropore volume) calculated using the $t$-plot method. ${ }^{\mathrm{d}} \mathrm{V}_{\text {meso }}$ (mesopore volume) calculated using the $\mathrm{BJH}$ method (from desorption). ${ }^{\mathrm{e}} \mathrm{R}_{\text {meso }}$ and $\mathrm{R}_{\text {macro }}$ calculated the ratio of mesopore and macropore by the BJH method (from desorption) [49].

\subsubsection{Acid Properties of Heteropolyacid Salt Catalysts}

The acidic properties of the samples were confirmed by $\mathrm{NH}_{3}$-TPD analyses and the results are presented in Figure 4 and Table 2. The number of acid sites represents the acid concentration of the catalyst, while the position of the peaks represents the strength of the acid sites. CuPW, FePW, and FeSiW have a similar amount of total acid sites of about $1.60 \mathrm{mmol} \cdot \mathrm{g}^{-1}$, while CuSiW has a much higher number of total acid sites $\left(2.12 \mathrm{mmol} \cdot \mathrm{g}^{-1}\right)$ because of the prominent high quantity of weak acid sites. For phosphotungstic acid salts, copper, and ferric salts have similar ratio of three kinds of acid sites. Copper silicotungstic has a high amount of weak acid sites $\left(1.02 \mathrm{mmol} \cdot \mathrm{g}^{-1}\right)$ and a low amount of medium acid sites $\left(0.07 \mathrm{mmol} \cdot \mathrm{g}^{-1}\right)$, while ferric silicotungstic has a similar amount of weak acid sites $\left(0.39 \mathrm{mmol} \cdot \mathrm{g}^{-1}\right)$ and medium acid sites $\left(0.47 \mathrm{mmol} \cdot \mathrm{g}^{-1}\right)$. Considering the strength of strong acid sites, it can be seen that the four catalysts show different behaviors. The peak values of $\mathrm{CuSiW}$ and $\mathrm{FeSiW}$ catalyst are $500{ }^{\circ} \mathrm{C}$ and $497^{\circ} \mathrm{C}$, while the results are $522^{\circ} \mathrm{C}$ and $560^{\circ} \mathrm{C}$ for CuPW and FePW catalysts, respectively. This indicates that the as-synthesized silicotungstic catalysts show similar acid strengths, which are weaker than that of phosphotungstic catalysts, especially for the FePW catalyst. The acid strength shows a correlation with the metal ion substitution obtained from the ICP-OES results, and the smaller substitution ratio of metal ion will leave more protons and result in stronger acid strength.

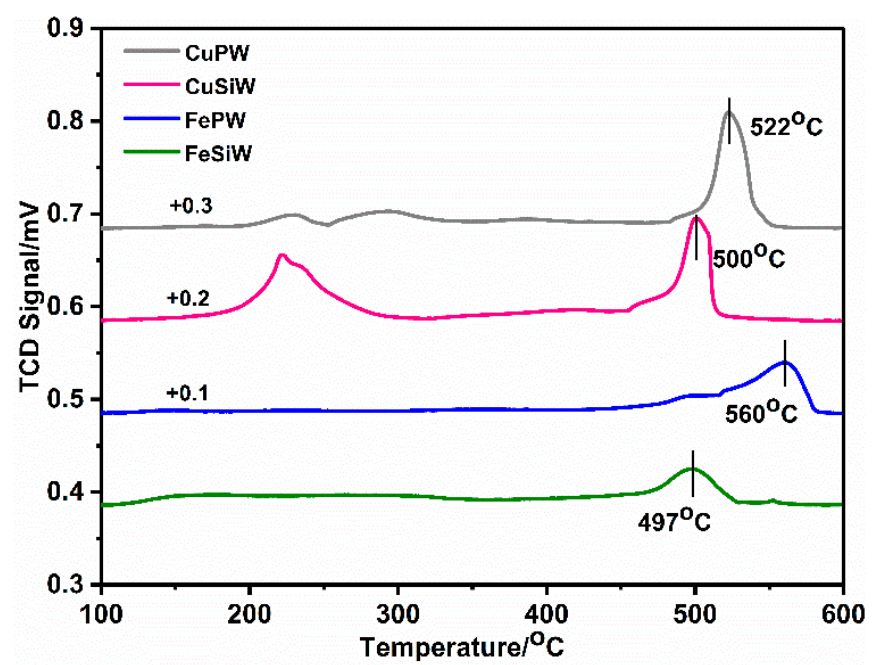

Figure 4. $\mathrm{NH}_{3}$-TPD curves of the as-synthesized heteropolyacid salt samples. 
Table 2. Acid sites distribution of the as-synthesized heteropolyacid salt samples.

\begin{tabular}{|c|c|c|c|c|}
\hline Sample Name & $\begin{array}{c}\text { Weak Acid Sites } \\
\text { (mmol/g) } \\
\left(100-250^{\circ} \mathrm{C}\right)\end{array}$ & $\begin{array}{c}\text { Medium Acid Sites } \\
(\mathrm{mmol} / \mathrm{g}) \\
\left(250-450^{\circ} \mathrm{C}\right)\end{array}$ & $\begin{array}{l}\text { Strong Acid Sites } \\
\text { (mmol/g) } \\
\left.\text { (Above } 450^{\circ} \mathrm{C}\right)\end{array}$ & Total (mmol/g) \\
\hline CuPW & 0.28 & 0.20 & 1.19 & 1.67 \\
\hline CuSiW & 1.02 & 0.07 & 1.03 & 2.12 \\
\hline FePW & 0.15 & 0.16 & 1.29 & 1.60 \\
\hline FeSiW & 0.39 & 0.47 & 0.82 & 1.68 \\
\hline
\end{tabular}

\subsection{Temperature Programmed Reaction of Methanol Conversion}

The product distribution of the temperature programmed methanol conversion using heteropolyacid salt and heteropolyacid catalysts were performed to explore their catalytic behavior and the results are shown in Figure 5. The evaluation temperature ends at $400{ }^{\circ} \mathrm{C}$ for the keggin structure will be destroyed at higher temperatures according to the IR results. These catalysts exhibit similar trend for the products distribution with increasing reaction temperature. Methanol conversion is very low at temperatures lower than $125^{\circ} \mathrm{C}$, then it increases rapidly with the increase of reaction temperature. During this period, DME is the predominant product (almost 100\%), the methanol conversion keeps at same high limits due to the equilibrium of methanol to DME reaction. Thereafter, DME selectivity decreases and hydrocarbons begin to form in the effluent when reaction temperature reaches $250^{\circ} \mathrm{C}$. This is because higher reaction temperature will push the equilibrium of methanol to DME reaction to the methanol side [35]. What's more, the formation of hydrocarbon pool species [50] at this temperature will consume methanol and DME, then produce light olefins and other hydrocarbon by-products. Therefore, at this temperature, light olefins such as ethylene and propylene can be obtained. When temperature is higher than about $350{ }^{\circ} \mathrm{C}$, it is interesting that the main product changes to methane with much higher methanol conversion during this period. Higher reaction temperature will lead to bigger conjugated structure hydrocarbon pool species [50], which will deactivate the catalyst. The formation of methane in the methanol conversion to hydrocarbons reaction is favored by high temperature and weak acid sites dominated on deactivated catalyst [51].

Figure $6 \mathrm{a}-\mathrm{c}$ give out the methanol conversion, DME and light olefins selectivity of the temperature programmed conversion of methanol over different catalysts. FeSiW catalyst has a relative high methanol conversion at low temperature ranging from $100{ }^{\circ} \mathrm{C}$ to $175{ }^{\circ} \mathrm{C}$, but lower conversion at temperatures higher than $225^{\circ} \mathrm{C}$. CuPW shows a completely methanol conversion at temperatures of $325^{\circ} \mathrm{C}$ till $375^{\circ} \mathrm{C}$, while $\mathrm{CuSiW}$ has a completely methanol conversion at temperatures of $375^{\circ} \mathrm{C}$ till $400^{\circ} \mathrm{C}$. Methanol conversion of HPW and HSiW catalysts are lower than FeSiW, but higher than other 3 salts before $200^{\circ} \mathrm{C}$. It was noticeable that they exhibit higher methanol conversion during $200-300^{\circ} \mathrm{C}$ than heteropolyacid salt catalysts. The DME selectivity retains almost at $100 \%$ from $125^{\circ} \mathrm{C}$ to $250{ }^{\circ} \mathrm{C}$ for HPW, HSiW, CuPW, CuSiW and FeSiW, while the DME selectivity for FePW is lower than $90 \%$ at $125-170{ }^{\circ} \mathrm{C}$ due to the formation of propane and low methanol conversion. Light olefins selectivity also shows similar trend at temperatures of $250-375^{\circ} \mathrm{C}$. CuPW has the highest light olefins selectivity of $34 \%$ at $280^{\circ} \mathrm{C}$. FeSiW and FePW have the highest light olefins selectivity of $28 \%$ at $315{ }^{\circ} \mathrm{C}$, whilst $\mathrm{CuSiW}$ has the highest light olefins selectivity of $44 \%$ at $310^{\circ} \mathrm{C}$. The light olefins selectivity for HPW is higher than its salts and the selectivity for HSiW are between the two salts. 

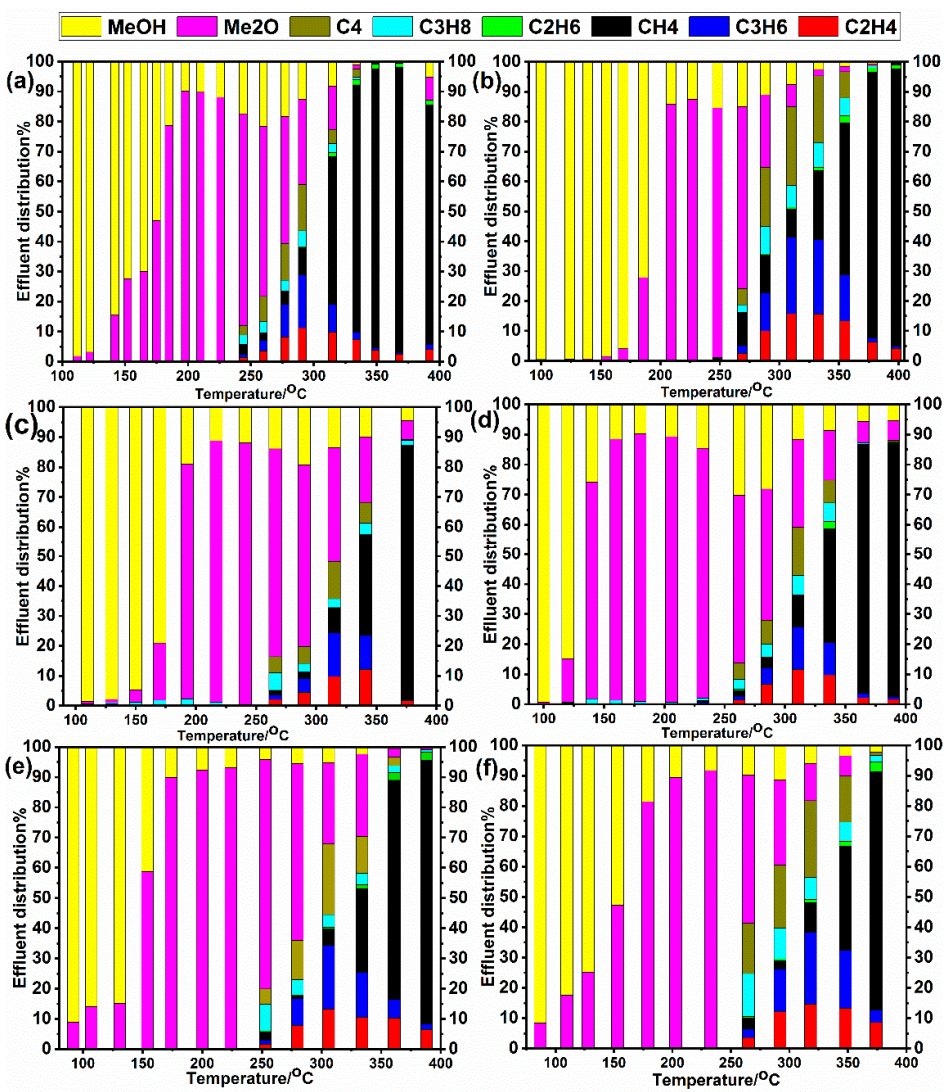

Figure 5. Effluent distribution of temperature programmed conversion of methanol on heteropolyacid salts and heteropolyacids. (a) CuPW, (b) CuSiW, (c) FePW, (d) FeSiW, (e) HPW, (f) HSiW, $\mathrm{m}_{\text {cat }}=3.00 \mathrm{~g}$, $\mathrm{N}_{2}$ flow rate $=20 \mathrm{~mL} / \mathrm{min}, \mathrm{WHSV}=0.25 \mathrm{~h}^{-1}$.
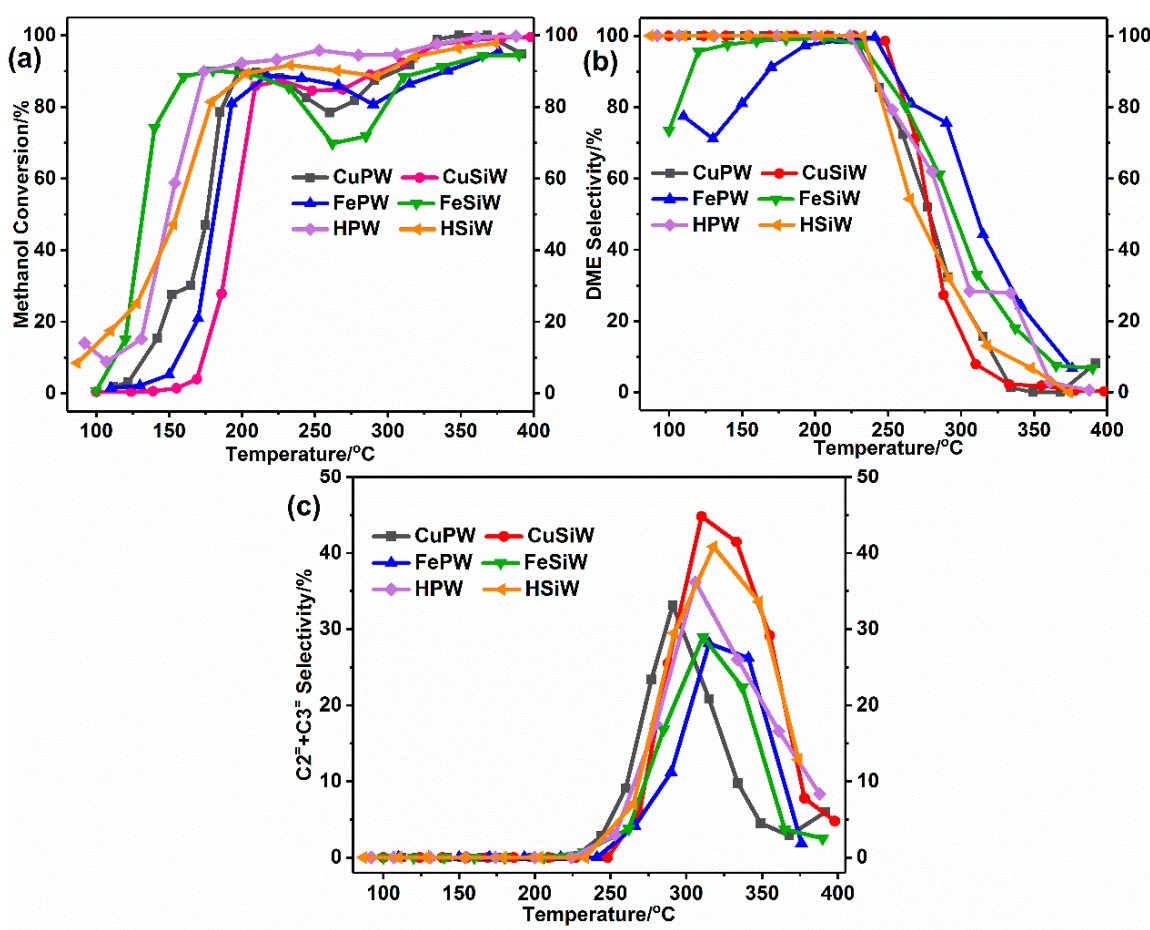

Figure 6. (a) Methanol conversion, (b) DME selectivity and (c) light olefins selectivity of temperature programmed conversion of methanol on heteropolyacid salts and heteropolyacids. $\mathrm{m}_{\text {cat }}=3.00 \mathrm{~g}$, $\mathrm{N}_{2}$ flow rate $=30 \mathrm{~mL} / \mathrm{min}, \mathrm{WHSV}=0.25 \mathrm{~h}^{-1}$. 


\subsection{Catalytic Performance of Heteropolyacid Salts for Methanol to DME}

Figure 7 shows the catalytic performance of heteropolyacid salts and heteropolyacids for the methanol conversion to DME at $200{ }^{\circ} \mathrm{C}$ in the fixed bed reactor with a space velocity of $2 \mathrm{~h}^{-1}$. The selectivity of DME for all catalysts are almost $100 \%$ at this temperature. Heteropolyacid salt catalysts have a much longer lifetime than the heteropolyacids. The catalysts show different tendencies in the initial $10 \mathrm{~h}$, but exhibit the same trend after $20 \mathrm{~h}$. The methanol conversion of CuSiW and FeSiW catalysts increase rapidly in the initial $20 \mathrm{~h}$, and then decrease slowly to $\sim 66 \%$ at a lifetime of $120 \mathrm{~h}$. Methanol conversion of CuPW catalyst increases slightly in the initial $3 \mathrm{~h}$, and then decreases slowly thereafter. The highest methanol conversion was $72 \%$ and the final rate was $48 \%$ after $100 \mathrm{~h}$ reaction. However, the methanol conversion of FePW catalysts was as high as $91 \%$ at the instant that methanol contacted the catalyst surface, but decreased rapidly to the lowest one of all the catalysts after $20 \mathrm{~h}$. HPW and HSiW catalysts showed the same trend with FePW, but with a faster decreasing rate. Thus, we can conclude that the silicotungstic acid salt catalysts have a quite long induction period, while the phosphotungstic acid salt catalysts have a very short induction time, especially for the FePW catalyst. Presumably, this is because the four catalysts possess different acid strengths according to the $\mathrm{NH}_{3}$-TPD results. Generally, higher acid site strength results in faster induction and higher methanol conversion in the beginning of the reaction. Heteropolyacids and FePW catalysts have the highest acid strength and the shortest induction period, while CuPW has a lower acid strength and longer induction period. Both FeSiW and CuSiW exhibited similar acid strengths lower than phosphotungstic acid salts, therefore, they show similar induction time and the same changing trend of methanol conversion, demonstrating that methanol conversion and lifetime are related to the strength of acid sites.

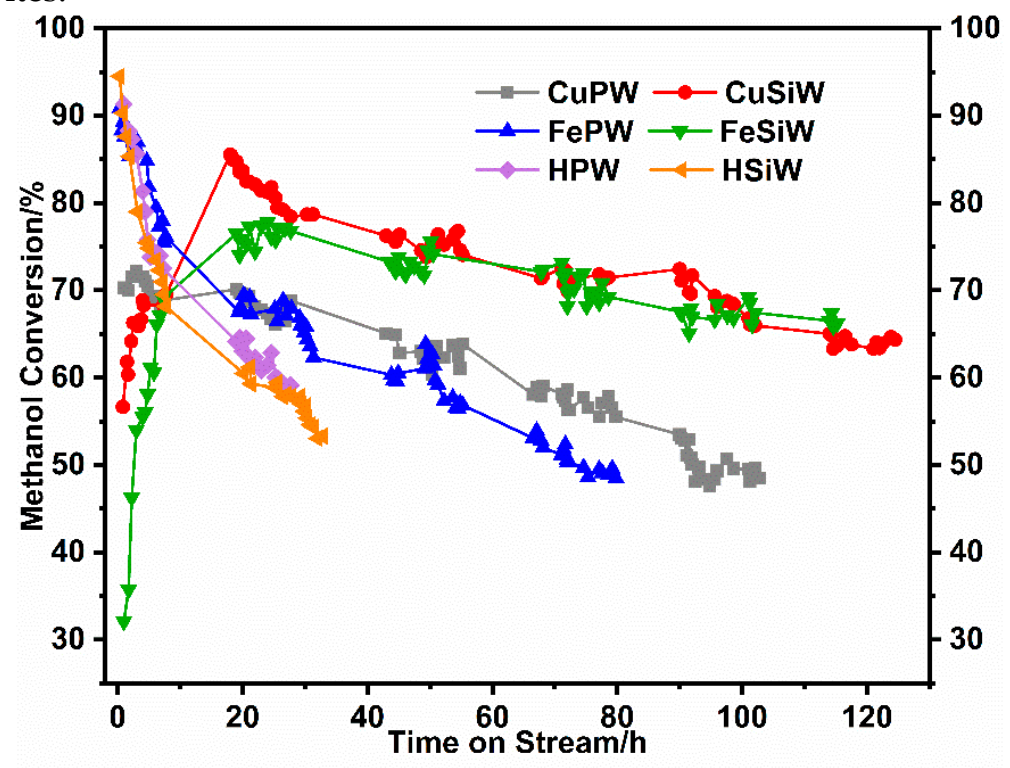

Figure 7. Time course for methanol dehydration on the heteropolyacid salts and heteropolyacids, $\mathrm{m}_{\text {cat }}=1.5 \mathrm{~g}$, reaction temperature: $200{ }^{\circ} \mathrm{C}, \mathrm{N}_{2}$ flow rate $=30 \mathrm{~mL} / \mathrm{min}, \mathrm{WHSV}=2 \mathrm{~h}^{-1}$, catalyst pre-treatment at $300{ }^{\circ} \mathrm{C}$ for $1 \mathrm{~h}$ under $\mathrm{N}_{2}$.

\section{Experimental}

\subsection{Chemical Reagents}

The heteropolyacids used were phosphotungstic acid $\left(\mathrm{H}_{3} \mathrm{PW}_{12} \mathrm{O}_{40} \cdot \mathrm{xH}_{2} \mathrm{O}\right.$, abbreviated as HPW, AR, Aladdin Biochemical Technology Co., Shanghai, China) and silicotungstic acid $\left(\mathrm{H}_{4} \mathrm{SiW}_{12} \mathrm{O}_{40}\right.$ $\cdot \mathrm{xH}_{2} \mathrm{O}$, abbreviated as HSiW, AR, Aladdin Biochemical Technology Co., Shanghai, China), while the salts used were $\mathrm{CuCl}_{2} \cdot 2 \mathrm{H}_{2} \mathrm{O}(\mathrm{AR}, 99 \%$, Guangzhou Chemical Reagent, Guangzhou, China) and $\mathrm{FeCl}_{3} \cdot 6 \mathrm{H}_{2} \mathrm{O}$ (AR, 99\%, Aladdin Biochemical Technology Co., Shanghai, China). The raw material 
used for catalyst evaluation was anhydrous methanol (AR, 99.5\%, Guangzhou Chemical Reagent, Guangzhou, China) which dehydrated with $4 \AA$ molecular sieves for more than 2 days, and SiC (AR, 99\%, Aladdin Biochemical Technology Co., Shanghai, China) was used as dispersing agent.

\subsection{Measurement}

Fourier transform infrared spectroscopy (FTIR) was conducted on a Perkin Elmer spectrum 100 spectrometer (PerkinElmer Inc., Waltham, Massachusetts, USA) equipped with a transmission infrared attachment to confirm the typical peaks of keggin structure of heteropolyacid salts. The IR spectrum was obtained by tableted $\mathrm{KBr}$ powder and tested at room temperature in the region from 4000 to $400 \mathrm{~cm}^{-1}$ at a step of $4 \mathrm{~cm}^{-1}$. Samples that calcined at different temperatures for IR test were prepared in muffle furnace (SX2, Shanghai Laboratory Instrument Works Co., Ltd., Shanghai, China) under air atmosphere for $2 \mathrm{~h}$. X-ray powder diffraction pattern (XRD) was collected to determine the crystalline phase of the samples on a RIGAKU D-MAX 2200 VPC diffractometer (Rigaku Corporation, Tokyo, Japan) operated at $40 \mathrm{kV}$ and $26 \mathrm{~mA}$ with a $\mathrm{Cu}-\mathrm{K} \alpha$ radiation $(\lambda=1.5406 \AA)$. Thermogravimetric (TG) analysis was performed to study the thermal performance of the samples on a PerkinElmer Pyris Diamond TG/DTA instrument (PerkinElmer Inc., Waltham, MA, USA). The sample was pretreated at $120^{\circ} \mathrm{C}$ for $30 \mathrm{~min}$ to remove the physically adsorbed water and followed by a decrease of the temperature to $50{ }^{\circ} \mathrm{C}$, then heated to $900{ }^{\circ} \mathrm{C}$ with a heating rate of $10 \mathrm{~K} / \mathrm{min}$ under air atmosphere. The acid properties of the as-synthesized heteropolyacid salts were studied by temperature programmed desorption of ammonia ( $\mathrm{NH}_{3}-\mathrm{TPD}$ ) with a Micromeritics Autochem II 2920 device (Micromeritics, Norcross, GA, USA). The as-synthesized samples (100 mg) were pre-treated under pure $\mathrm{He}$ at $200^{\circ} \mathrm{C}$ for $1 \mathrm{~h}$ to remove the adsorbed gas and water, then stabled at $100^{\circ} \mathrm{C}$ to saturate the sample with gaseous $\mathrm{NH}_{3}$ under $\mathrm{NH}_{3} / \mathrm{He}$ with a flow of $50 \mathrm{~mL} \cdot \mathrm{min}^{-1}$ and kept for $0.5 \mathrm{~h}$, removed the physically adsorbed $\mathrm{NH}_{3}$ under $\mathrm{He}$ flow for $0.5 \mathrm{~h}$, finally measured the amount of desorbed $\mathrm{NH}_{3}$ with a temperature programming process at a heating rate of $10 \mathrm{~K} / \mathrm{min}$ from $100{ }^{\circ} \mathrm{C}$ to $600{ }^{\circ} \mathrm{C}$ under He flow $(50 \mathrm{~mL} / \mathrm{min}$ ). A Micromeritics ASAP 2460 analyzer (Micromeritics, Norcross, GA, USA) was applied to measure the Nitrogen adsorption-desorption isotherms at $77.15 \mathrm{~K}$, the sample (about $0.5 \mathrm{~g}$ ) were degassed at $100{ }^{\circ} \mathrm{C}$ under vacuum overnight. The total surface area was calculated based on the Brunauer-Emmett-Teller (BET) equation according to the linear part $(0.05<\mathrm{P} / \mathrm{P} 0<0.30)$ of the adsorption curves. The micropore volume, external surface area, and micropore surface area were evaluated by the $t$-plot method using the linear part of $0.35<\mathrm{P} / \mathrm{P} 0<0.50$ with a principle of minimal slope. The mesopore volume was calculated using the Barrett-Joyner-Halenda (BJH) method from the desorption curve. The pore volume distribution was obtained from the density functional theory (DFT) method. Elemental compositions of the catalyst were confirmed by inductively coupled plasma optical emission spectrometry (ICP-OES) analyses on a Perkin-Elmer Optima 8300 instrument (PerkinElmer Inc., Waltham, MA, USA). The catalyst was dissolved by concentrated nitric acid and drops of HF solution with hydrothermal treatment at $70{ }^{\circ} \mathrm{C}$ overnight in an autoclave, then diluted with deionized water to keep a 5 wt. \% acidity.

\subsection{Synthesis of Heteropolyacid Salts Catalyst}

Typically, $0.01 \mathrm{~mol}$ heteropolyacids (HPW or HSiW) were dissolved in $100 \mathrm{~mL}$ deionized water in a beaker and heated to $80^{\circ} \mathrm{C}$ under water bath, then 1.5 or 2 molar equivalents $\mathrm{CuCl}_{2} \cdot 2 \mathrm{H}_{2} \mathrm{O}$ were added to the HPA solution and continuously stirred for 3 hours, while the molar ratio for $\mathrm{FeCl}_{3} \cdot 6 \mathrm{H}_{2} \mathrm{O}$ were 1 and 1.33 for HPW and HSiW, respectively. Then, the solutions were filtered and evaporative crystallized to remove the undissolved and dissolved impurities. Finally, the products were dried at $120{ }^{\circ} \mathrm{C}$ overnight and finely ground for further use.

\subsection{Catalytic Evaluation}

The performance of the catalyst for methanol conversion reaction was carried on a metallic tubular fixed-bed reactor (10-mm inner diameter) under atmospheric pressure; the reaction temperature was 
confirmed by a K-type thermocouple placed into the catalytic bed directly. Flow rates were controlled by Brooks 5850E (Brooks instrument, Hatfield, PA, USA) mass flow controllers. In a typical process, $3 \mathrm{~g}$ of the thoroughly dried heteropolyacid salts catalyst was mixed uniformly with $3 \mathrm{~g} \mathrm{SiC}$ powder to prevent heat concentration and loaded in the tubular fixed-bed reactor. The species and quantities of the products were confirmed by an online gas chromatograph (Tianmei, GC-7890-II, Tianmei Scientific Instrument Co., Shanghai, China) which equipped with a Plot-Q column (RESTEK, Rt@-Q-Bond, $30 \mathrm{~m}$, $0.32 \mathrm{~mm}$ ID, $10 \mathrm{um} \mathrm{df}$, Beijing, China) and a flame ionization detector (FID). The effluent distribution of the products were calculated based on the amounts of the $\mathrm{CH}_{2}$ species. Methanol conversion and product selectivity were calculated by the mass balance method as follows:

$$
\mathrm{CH}_{3} \mathrm{OH} \text { conversion } \%=\frac{[\text { Methanol consumed }]}{[\text { Methanol total }]} \times 100 \%
$$

$$
\text { Product } i \text { selectivity } \%=\frac{[\text { Number of methanol turned into } i \text { product }]}{[\text { Methanol consumed }]} \times 100 \%
$$

Temperature programmed reaction procedure: the stock was fed by bubbling the liquid methanol (at $30^{\circ} \mathrm{C}$ ) through the flowing carrier gas $\left(\mathrm{N}_{2}\right)$ with a rate of $30 \mathrm{~mL} \cdot \mathrm{min}^{-1}$, corresponding to a weight hourly space velocity (WHSV) of $0.25 \mathrm{~h}^{-1}$ (confirmed by the weight of the consumed methanol, 17.8 vol. $\%$ methanol). The initial temperature was set at $80{ }^{\circ} \mathrm{C}$ with methanol flowing during the heating process. The temperature interval was set as $25^{\circ} \mathrm{C}$ and stabled for $0.5 \mathrm{~h}$ for each temperature point, and the GC spectrum data were collected twice for each temperature point and the run time for each spectrum was $20 \mathrm{~min}$.

In the stability tests of DME production reaction, the catalyst $\left(\mathrm{m}_{\mathrm{cat}}=1.5 \mathrm{~g}\right.$, mixed with $\left.1.5 \mathrm{~g} \mathrm{SiC}\right)$ was pre-treated under $\mathrm{N}_{2}$ atmosphere at $300^{\circ} \mathrm{C}$ for $1 \mathrm{~h}$ without bubbling methanol, then decreased the reaction temperature to $200{ }^{\circ} \mathrm{C}$ and bubbled methanol (at $50{ }^{\circ} \mathrm{C}$ ) through $\mathrm{N}_{2}$ with a rate of $30 \mathrm{~mL} \cdot \mathrm{min}^{-1}$, corresponding to a weight hourly space velocity (WHSV) of $2.0 \mathrm{~h}^{-1}$ (46.0 vol. \% methanol). Mass and heat transfer limitations were ruled out by theoretical calculation (see Supplementary Materials) according to the criteria in the references [52-56].

\section{Conclusions}

In summary, phosphotungstic and silicotungstic acid salt catalysts were synthesized via a simple replacement reaction. The as-synthesized catalysts showed $100 \%$ DME selectivity at $175-225{ }^{\circ} \mathrm{C}$ and long lifetime for methanol to DME reaction at $200{ }^{\circ} \mathrm{C}$. They also showed a quite high ethylene and propylene selectivity at higher temperatures. Meanwhile, effluent distribution of methanol conversion to hydrocarbons at different temperatures can be monitored by the temperature programmed reaction. All catalysts exhibited quite different induction behavior in the stability test due to the differences in acid strengths, and the induction period had a positive correlation with the strength of strong acid sites. The heteropolyacid salt catalysts showed much longer lifetimes than their heteropolyacids. This work provides a simple way for effective utilization of heteropolyacid for methanol conversion reaction. The methanol conversion to hydrocarbons, especially DME, can be effectively performed at different temperature using one catalyst.

Supplementary Materials: The following are available online at http://www.mdpi.com/2073-4344/9/4/320/s1.

Author Contributions: Y.Y., M.X., and Y.M. conceived and designed the experiments; Y.Y. and D.S. performed the experiments and analyzed the data; S.W. and L.S. contributed to the analysis tools. Y.Y. wrote this paper.

Funding: This research was funded by the National Natural Science Foundation of China (Grant No. 21376276), Guangdong Province Sci. \& Tech. Bureau (Grant No. 2017B090901003, 2016B010114004, 2016A050503001), and the Fundamental Research Funds for the Central Universities.

Acknowledgments: The authors would like to thank the National Natural Science Foundation of China (Grant No. 21376276), Guangdong Province Sci. \& Tech. Bureau (Grant No. 2017B090901003, 2016B010114004, 2016A050503001), and the Fundamental Research Funds for the Central Universities for the financial support of this work. 
Conflicts of Interest: The authors declare no conflict of interest.

\section{References}

1. Mokrani, T.; Scurell, M. Gas Conversion to Liquid Fuels and Chemicals: The Methanol Route-Catalysis and Processes Development. Catal. Rev. Sci. Eng. 2009, 51, 1-145. [CrossRef]

2. Galvita, V.V.; Semin, G.L.; Belyaev, V.D.; Yurieva, T.M.; Sobyanin, V.A. Production of hydrogen from dimethyl ether. Appl. Catal. A Gen. 2001, 216, 85-90. [CrossRef]

3. Takeishi, K.; Suzuki, H. Steam reforming of dimethyl ether. Appl. Catal. A Gen. 2004, 260, 111-117. [CrossRef]

4. Ramos, F.S.; Duarte de Farias, A.M.; Borges, L.E.P.; Monteiro, J.L.; Fraga, M.A.; Sousa-Aguiar, E.F.; Appel, L.G. Role of dehydration catalyst acid properties on one-step DME synthesis over physical mixtures. Catal. Today 2005, 101, 39-44. [CrossRef]

5. Dermeche, L.; Salhi, N.; Hocine, S.; Thouvenot, R.; Rabia, C.; Mol, J. Effective Dawson type polyoxometallate catalysts for methanol oxidation. Catal. A Chem. 2012, 356, 29-35. [CrossRef]

6. Youn, I.M.; Park, S.H.; Roh, H.G.; Lee, C.S. Investigation on the fuel spray and emission reduction characteristics for dimethyl ether (DME) fueled multi-cylinder diesel engine with common-rail injection system. Fuel Process. Technol. 2011, 92, 1280-1287. [CrossRef]

7. Wood, D.A.; Nwaoha, C.; Towler, B.F. Gas-to-liquids (GTL): A review of an industry offering several routes for monetizing natural gas. J. Nat. Gas Sci. Eng. 2012, 9, 196-208. [CrossRef]

8. Fleisch, T.H.; Basu, A.R.; Sills, A. Introduction and advancement of a new clean global fuel: The status of DME developments in China and beyond. J. Nat. Gas Sci. Eng. 2012, 9, 94-107. [CrossRef]

9. Pontzen, F.; Liebner, W.; Gronemann, V.; Rothaemel, M.; Ahlers, B. $\mathrm{CO}_{2}$-based methanol and DME Efficient technologies for industrial scale production. Catal. Today 2011, 171, 242-250. [CrossRef]

10. Hu, H.; Cao, F.H.; Ying, W.Y.; Sun, Q.W.; Fang, D.Y. Study of coke behavior of catalyst during methanol-to-olefins process based on a special TGA reactor. Chem. Eng. J. 2010, 160, 770-778. [CrossRef]

11. Liu, Z.M.; Sun, C.L.; Wang, G.W.; Wang, Q.X.; Cai, G.Y. New progress in R\&D of lower olefin synthesis. Fuel Process. Technol. 2000, 62, 161-172.

12. Gertsberg, L.Y.; Surzhan, G.P.; Barvin, V.I. Efficient method of dimethyl sulfate production. Tr. Buryat. Inst. Estestv. Nauk Buryat. Filial Sib. Otd. Akad. Nauk SSSR 1971, 10, 228-229.

13. Liu, D.H.; Huang, X.; Hu, L.; Fang, D.Y.; Ying, W.Y.; Chen, D.S. Synthesis of ethylidene diacetate from dimethyl ether, $\mathrm{CO}$ and $\mathrm{H}_{2}$. J. Nat. Gas Chem. 2010, 19, 165-168. [CrossRef]

14. Bahmanpour, A.M.; Héroguel, F.; Baranowski, C.J.; Luterbacher, J.S.; Kröcher, O. Selective synthesis of dimethyl ether on eco-friendly K10 montmorillonite clay. Appl. Catal. A Gen. 2018, 560, 165-170. [CrossRef]

15. Carr, R.T.; Neurock, M.; Iglesia, E. Catalytic consequences of acid strength in the conversion of methanol to dimethyl ether. J. Catal. 2011, 278, 78-93. [CrossRef]

16. Moses, P.G.; Nørskov, J.K. Methanol to Dimethyl Ether over ZSM-22: A Periodic Density Functional Theory Study. ACS Catal. 2013, 3, 735-745. [CrossRef]

17. Ladera, R.; Finocchio, E.; Rojas, S.; Busca, G.; Fierro, J.L.G.; Ojeda, M. Supported WOx-based catalysts for methanol dehydration to dimethyl ether. Fuel 2013, 113, 1-9. [CrossRef]

18. Arena, F.; Spadaro, L.; Di Blasi, L.; Bonura, G.; Frusteri, F. Integrated synthesis of dimethylether via $\mathrm{CO}_{2}$ hydrogenation. Stud. Surf. Sci. Catal. 2004, 147, 385-390.

19. Bonura, G.; Cordaro, M.; Spadaro, L.; Cannilla, C.; Arena, F.; Frusteri, F. Hybrid Cu-ZnO-ZrO $2 / \mathrm{H}_{-} \mathrm{ZSM}-5$ system for the direct synthesis of DME by $\mathrm{CO}_{2}$ hydrogenation. Appl. Catal. B-Environ. 2013, 140-141, 16-24. [CrossRef]

20. Bonura, G.; Cordaro, M.; Cannilla, C.; Mezzapica, A.; Spadaro, L.; Arena, F.; Frusteri, F. Catalytic behavior of a bifunctional system for the one step synthesis of $\mathrm{DME}$ by $\mathrm{CO}_{2}$ hydrogenation. Catal. Today 2014, 228, 51-57. [CrossRef]

21. Raoof, F.; Taghizadeh, M.; Eliassi, A.; Yaripour, F. Effects of temperature and feed composition on catalytic dehydration of methanol to dimethyl ether over $\gamma$-alumina. Fuel 2008, 87, 2967-2971. [CrossRef]

22. Tavan, Y.; Khosravi Nikou, M.R.; Shariati, A. Effect of the P/Al ratio on the performance of modified HZSM-5 for methanol dehydration reaction. J. Ind. Eng. Chem. 2014, 20, 668-673. [CrossRef]

23. Akarmazyan, S.S.; Panagiotopoulou, P.; Kambolis, A.; Papadopoulou, C.; Kondarides, D.I. Methanol dehydration to dimethyl ether over Al2O3 catalysts. Appl. Catal. B-Environ. 2014, 145, 136-148. [CrossRef] 
24. Sabour, B.; Peyrovi, M.H.; Hamoule, T.; Rashidzadeh, M. Catalytic dehydration of methanol to dimethyl ether (DME) over Al-HMS catalysts. J. Ind. Eng. Chem. 2014, 20, 222-227. [CrossRef]

25. Sang, Y.; Li, H.; Zhu, M.; Ma, K.; Jiao, Q.; Wu, Q. Catalytic performance of metal ion doped MCM-41 for methanol dehydration to dimethyl ether. J. Porous Mater. 2013, 20, 1509-1518. [CrossRef]

26. Ladera, R.; Finocchio, E.; Rojas, S.; Fierro, J.L.G.; Ojeda, M. Supported niobium catalysts for methanol dehydration to dimethyl ether: FTIR studies of acid properties. Catal. Today 2012, 192, 136-143. [CrossRef]

27. Lertjiamratn, K.; Praserthdam, P.; Arai, M.; Panpranot, J. Modification of acid properties and catalytic properties of $\mathrm{AlPO}_{4}$ by hydrothermal pretreatment for methanol dehydration to dimethyl ether. Appl. Catal. A 2010, 378, 119-123. [CrossRef]

28. Vishwanathan, V.; Roh, H.S.; Kim, J.W.; Jun, K.W. Surface Properties and Catalytic Activity of $\mathrm{TiO}_{2}-\mathrm{ZrO}_{2}$ Mixed Oxides in Dehydration of Methanol to Dimethyl Ether. Catal. Lett. 2004, 96, 23-28. [CrossRef]

29. Tokay, K.C.; Dogu, T.; Dogu, G. Dimethyl ether synthesis over alumina based catalysts. Chem. Eng. J. 2012, 184, 278-285. [CrossRef]

30. Ladera, R.M.; Ojeda, M.; Fierro, J.L.G.; Rojas, S. $\mathrm{TiO}_{2}$-supported heteropoly acid catalysts for dehydration of methanol to dimethyl ether: Relevance of dispersion and support interaction. Catal. Sci. Technol. 2015, 5, 484-491. [CrossRef]

31. Xu, M.; Lunsford, J.H.; Goodman, D.W.; Bhattacharayya, A. Synthesis of dimethyl ether (DME) from methanol over solid-acid catalysts. Appl. Catal. A 1997, 149, 289-301. [CrossRef]

32. Takeguchi, T.; Yanagisawa, K.; Inui, T.; Inoue, M. Effect of the property of solid acid upon syngas-to-dimethyl ether conversion on the hybrid catalysts composed of Cu-Zn-Ga and solid acids. Appl. Catal. A 2000, 192, 201-209. [CrossRef]

33. Ladera, R.M.; Fierro, J.L.G.; Ojeda, M.; Rojas, S. $\mathrm{TiO}_{2}$-supported heteropoly acids for low-temperature synthesis of dimethyl ether from methanol. J. Catal. 2014, 312, 195-203. [CrossRef]

34. Schnee, J.; Gaigneaux, E.M. Lifetime of the $\mathrm{H}_{3} \mathrm{PW}_{12} \mathrm{O}_{40}$ heteropolyacid in the methanol-to-DME process: A question of pre-treatment. Appl. Catal. A Gen. 2017, 538, 174-180. [CrossRef]

35. Alharbi, W.; Kozhevnikova, E.F.; Kozhevnikov, I.V. Dehydration of Methanol to Dimethyl Ether over Heteropoly Acid Catalysts: The Relationship between Reaction Rate and Catalyst Acid Strength. ACS Catal. 2015, 5, 7186-7193. [CrossRef]

36. Jones, A.L.; Carr, R.T.; Zones, S.I.; Iglesia, E. Acid strength and solvation in catalysis by MFI zeolites and effects of the identity, concentration and location of framework heteroatoms. J. Catal. 2014, 312, 58-68. [CrossRef]

37. Hibi, T.; Takahashi, K.; Okuhara, T.; Misono, M.; Yoneda, Y. Catalysis by heteropoly compounds. X. Synthesis of lower olefins by conversion of dimethyl ether over 12-tungstophosphates. Appl. Catal. 1986, 24, 69-83. [CrossRef]

38. Highfield, J.C.; Moffat, J.B. Characterization of sorbed intermediates and implications for the mechanism of chain growth in the conversion of methanol and ethanol to hydrocarbons over 12-tungstophosphoric acid using infrared photoacoustic spectroscopy. J. Catal. 1986, 98, 245-258. [CrossRef]

39. Seo, C.W.; Jung, K.D.; Lee, K.Y.; Yoo, K.S. Dehydration of methanol over Nordstrandite based catalysts for dimethyl ether synthesis. J. Ind. Eng. Chem. 2009, 15, 649-652. [CrossRef]

40. Çiftci, A.; Varisli, D.; Cem Tokay, K.; Asli Sezgi, N.; Dogu, T. Dimethyl ether, diethyl ether \& ethylene from alcohols over tungstophosphoric acid based mesoporous catalysts. Chem. Eng. J. 2012, 207, 85-93.

41. Micek-Ilnicka, A.; Bielanska, E.; Litynska-Dobrzynska, L.; Bielanski, A. Carbon nanotubes, silica and titania supported heteropolyacid $\mathrm{H}_{3} \mathrm{PW}_{12} \mathrm{O}_{40}$ as the catalyst for ethanol conversion. Appl. Catal. A 2012, 421, 91-98. [CrossRef]

42. Varisli, D.; Tokay, C.K.; Ciftci, A.; Dogu, T.; Dogu, G. Methanol dehydration reaction to produce clean diesel alternative dimethylether over mesoporous aluminosilicate-based catalysts. Turk. J. Chem. 2009, 33, 355-366.

43. Yoshio, O.; Toshihide, B.; Junya, S.; Tominaga, K. Conversion of methanol into hydrocarbons catalysed by metal salts of heteropolyacids. J. Chem. Soc. Chem. Commun. 1981, 9, 400-401.

44. Toshihide, B.; Junya, S.; Yoshio, O. The Conversion of Methanol into Hydrocarbons over Metal Salts of Heteropolyacids. Bull. Chem. Soc. Jpn. 1982, 55, 2657-2658.

45. Nakka, L.; Molinari, J.E.; Wachs, I.E. Surface and Bulk Aspects of Mixed Oxide Catalytic Nanoparticles: Oxidation and Dehydration of $\mathrm{CH}_{3} \mathrm{OH}$ by Polyoxometallates. J. Am. Chem. Soc. 2009, 131, 15544-15554. [CrossRef] 
46. Rocchiccioli-Deltcheff, C.; Fournier, M.; Franck, R.; Thouvenot, R. Vibrational investigations of polyoxometalates. 2. Evidence for anion-anion interactions in molybdenum (VI) and tungsten (VI) compounds related to the Keggin structure. Inorg. Chem. 1983, 22, 207-226. [CrossRef]

47. Bielańnski, A.; Datka, J.; Gil, B.; Małecka-Lubańska, A.; Micek-Ilnicka, A. FTIR study of hydration of dodecatungstosilicic acid. Catal. Lett. 1999, 57, 61-64. [CrossRef]

48. Marcì, G.; García-López, E.; Vaiano, V.; Sarno, G.; Sannino, D.; Palmisano, L. Keggin heteropolyacids supported on $\mathrm{TiO}_{2}$ used in gas-solid (photo)catalytic propene hydration and in liquid-solid photocatalytic glycerol dehydration. Catal. Today 2017, 281, 60-70. [CrossRef]

49. Vita, A.; Italiano, G.; Ashraf, M.A.; Pino, L.; Specchia, S. Syngas production by steam and oxy-steam reforming of biogas on monolith-supported $\mathrm{GeO}_{2}$-based catalysts. Int. J. Hydrogen Energy 2018, 43, 11731-11744. [CrossRef]

50. Borodina, E.; Meirer, F.; Lezcano-González, I.; Mokhtar, M.; Asiri, A.M.; Al-Thabaiti, S.A.; Basahel, S.N.; Ruiz-Martinez, J.; Wechhuysen, B.M. Influence of the Reaction Temperature on the Nature of the Active and Deactivating Species during Methanol to Olefins Conversion over H-SSZ-13. ACS Catal. 2015, 5, 992-1003. [CrossRef]

51. Zhao, W.P.; Zhang, B.Z.; Wang, G.R.; Guo, H.C. Methane formation route in the conversion of methanol to hydrocarbons. J. Energy Chem. 2014, 23, 201-206. [CrossRef]

52. Arena, F.; Di Chio, R.; Fazio, B.; Espro, C.; Spiccia, L.; Palella, A.; Spadaro, L. Probing the functionality of nanostructured $\mathrm{MnCeO}_{\mathrm{x}}$ catalysts in the carbon monoxide oxidation Part I. Influence of cerium addition on structure and CO oxidation activity. Appl. Catal. B-Environ. 2017, 210, 14-22. [CrossRef]

53. Ortega, C.; Rezaei, M.; Hessel, V.; Kolb, G. Methanol to dimethyl ether conversion over a ZSM-5 catalyst: Intrinsic kinetic study on an external recycle reactor. Chem. Eng. J. 2018, 347, 741-753. [CrossRef]

54. Weisz, P.B.; Prater, C.D. Interpretation of measurements in experimental catalysis. In Advances in Catalysis; Frankenburg, W.G., Komarewsky, V.I., Rideal, E.K., Eds.; Academic Press Inc.: Salt Lake City, UT, USA, 1954; Volume 6, pp. 143-196.

55. Gupta, A.S.; Thodos, G. Mass and heat in the flow of fluids through fixed and fluidized beds of spherical particles. AIChE J. 1962, 8, 608-610. [CrossRef]

56. Anderson, J.B. A criterion for isothermal behaviour of a catalyst pellet. Chem. Eng. Sci. 1963, 18, 147-148.

(C) 2019 by the authors. Licensee MDPI, Basel, Switzerland. This article is an open access article distributed under the terms and conditions of the Creative Commons Attribution (CC BY) license (http:/ / creativecommons.org/licenses/by/4.0/). 